Please note this is the Accepted Manuscript of an article published by Taylor \& Francis in Translation Studies.

Orrego-Carmona, David. 2019. A holistic approach to non-professional subtitling from a functional quality perspective. Translation Studies, pp.1-17. DOI: https://doi.org/10.1080/14781700.2019.1686414

A holistic approach to non-professional subtitling from a functional quality perspective

\title{
David Orrego-Carmona
}

School of Languages and Social Sciences, Aston University, Birmingham, UK

Department of Linguistics and Language Practice, University of the Free State, Bloemfontein, South Africa

Email: $\underline{\text { d.orrego-carmona@aston.ac.uk }}$

This article studies non-professional subtitling (NPS) within a holistic framework combining Chesterman's propositions of functional quality and expectancy norms. NPS communities emerged due to discomfort among users regarding translated audiovisual products. The assessment of the production and reception conditions of NPS through a review of studies reveals that quality is relevant on both sides. On the production side, non-professional subtitlers have defined procedures aiming at ensuring the quality of the subtitles. On the reception side, users have developed a conscious approach to select the subtitles they want to use. For users, access and speed in the release of the subtitles are key when choosing subtitles. Results indicate that NPS fulfills the users' expectations because the communities are geared towards producing subtitles that address the users' needs. This article calls for further exploration of NPS settings to expand the notions of quality and translation under the current conditions.

Key words: non-professional subtitling, quality, users, prosumers, volunteer translator, reception

\section{Introduction}

Recent social and technological developments are happening in the practice of translation at a global scale. These changes are not only driven by professional translators but by many other 
forces affecting translation spaces, including technologies, and the broader industry. One vibrant area that is reshaping the landscape of translation activities is non-professional subtitling (NPS). The intensification of volunteer translators' activities in the last two decades has resulted in the emergence of a busy field that scholars have referred to as "community translation”, "social translation” (O’Hagan 2011), "volunteer translation” (Pym 2011) and “collaborative translation" (Fernández Costales 2012) among other labels that tend to overlap. According to Miguel Jiménez-Crespo (2015), social translation encompasses collaborative, volunteer, crowdsourcing and community translation manifestations, and is large and heterogeneous in nature. The activities range from self-organized, non-professional subtitling groups to centralized and controlled crowdsourcing environments. Among these settings and manifestations, the shared key feature is the empowerment of users: regular users, acting as prosumers (O’Hagan 2009) who morph into translators for communities of people like them, with whom they share common interests.

Apart from altering the way translations are done, this disruption also has some bearing on how scholars approach NPS and non-professional translation in general. One of the main concerns that has been brought up regarding these manifestations of translation is that of quality. Concerns regarding quality and quality assessment are essential in both translation studies (TS) (House 2014; Williams 2009) and the translation industry. The complexity of defining quality and quality models has been tackled by scholars as well as professionals and professional bodies such as TAUS, CEN, or ISO (O'Brien 2012), which see quality as a key aspect of the provision of translation services. It is thus understandable that non-professional translation - a phenomenon that many see as a threat to the profession - is scrutinized and judged in terms of quality. With its expansion and reach, it is only natural to assume that non-professional translation practice is a driving force in the conceptualization of quality in current translation spaces. The incursions of users-turned-translators into translation spaces has caused vibrant discussions about quality.

Drawing on a series of studies, in this article I claim non-professional translation should be studied in a comprehensive manner that assesses quality based on the conditions in which translations come to be and the situations in which they are used. While it largely relies on previous publications (Orrego-Carmona 2011, 2014, 2015, 2016b; Pym, Orrego-Carmona, and Torres-Simón 2016; Orrego-Carmona and Richter 2018), this article presents a new and thorough analysis of the results to provide a solid framework to study the NPS phenomenon. 


\section{Quality in non-professional subtitling}

One of the first instances we have of fansubbing being studied in academic circles is presented by Abé Mark Nornes (1999), an Asian cinema scholar. Nornes argues that mainstream subtitling practices are "corrupt" since they tend to hide the work of subtitlers, smooth over the textual violence and otherness of the source text while still pretending to "bring the audience to an experience of the foreign" (Nornes 1999, 18). In contrast, Nornes claims abusive subtitling (which is the term he uses to refer to subtitles done by fans) experiments with language and its qualities to highlight the "fact of translation" and make the foreign origin of the film evident to viewers $(1999,17)$.

While Nornes sees abusive subtitling as a liberating activity that breaks with the conventions imposed by professional, historical and geopolitical ideologies, TS scholars have been more cautious, and even wary, in its approach to non-professional subtitling. Translation studies started to pay attention to non-professional subtitling in the 2000 s and the notion of quality was put on the table as soon as scholars started addressing the phenomenon:

Given this state of affairs, it is not surprising that the quality of the translations circulating on Internet is very often below par, although on occasions some fansubs do not have anything to envy to the quality of the licensed translations, commercially distributed on DVD or broadcast on television. (Díaz Cintas and Muñoz Sánchez 2006, 46)

The accentuated focus on quality has caused non-professional subtitles (and non-professional translations) to be often judged according to professional notions of translation and compared against professional standards. A common focus in the studies exploring fansubbing and other forms of non-professional translation has been the search for errors in the translations: scholars have attempted to signal and systematize the errors in NPS to point out the low quality. For instance, Łukasz Bogucki (2009) compares a professional version against a nonprofessional version of the subtitles for The Lord of the Rings: The Fellowship of the Ring into Polish. Although he recognizes that the production conditions of both are very different, he argues that the low quality of amateur subtitling, partly due to the poor cam-recorded video material, renders the study of this type of translation useless for academics since they are simply not comparable. Given that fansubbers in many cases work with low-quality original videos and without scripts, in his view, "[i]f [...] amateur subtitling continues to be done on the basis of incomplete information, it will necessarily also be imperfect and not available to academic study due to its high degree of unpredictability" (Bogucki 2009, 57). Along the 
same lines, Francesca La Forgia and Tonin (2009) show that fan translations into Italian and Spanish are clearly of lower quality than their professional counterparts. Likewise, William Hanes (2011) points out the mistakes made by Portuguese fan translators, and Mateusz Sajna (2013) explores the error-prone areas of fansubbing into Polish. Even María Ferrer Simó (2005), in a study that considers fansubbed versions as alternative translations and a factor influencing audiences, makes a point about translation and transcription errors being characteristic of fansubs.

Most of these studies discuss the environment where NPS occurs. They also present or hint at the specific characteristics of NPS. However, all of them still focus on the detection of errors from a quality perspective that does not consider these specificities.

In academic circles, some even argue that non-professional subtitles should not be studied at all (Cornu 2013) given that this would legitimize an often illegal activity that undermines the profession. From an academic perspective, the existence, growth, and acceptance of NPS activities make it imperative to subject them to scrutiny in terms of quality, as evidenced by a growing body of literature in the area. However, given that the constraints and roles of the agents involved in non-professional translation are different from those found in professional settings, the concept of quality that is used to assess nonprofessional subtitles should be revised under the emerging conditions of non-professional settings.

\section{Functional quality and expectancy norms}

The studies mentioned above highlight an essential aspect in the conceptualization of quality of translations: they assume that quality depends primarily on the translated product. Consequently, their approach to assessing quality focuses on the linguistic aspects of the fansubbed translations. This concept of quality grants a higher relevance to the source texttarget text relation and entails the type of comparative evaluation process as the rule to judge a translation. However, recent approaches maintain that the concept of quality implicit and embedded in different translation environments and translatorial actions can be multifaceted. TS has moved from the assumption that translations should be judged according to a theory of linguistic-based equivalence (Nida 1964; Catford 1965) to more functional approaches that take into account other elements that are constantly redefined. The evolution of the concept of quality in TS has allowed for different concepts of functional quality to be proposed and discussed, ranging from the functional approaches promoted by Katharina Reiss and Hans 
Vermeer (2015) or Christiane Nord (Reiss and Vermeer 2015; Nord 1997) to professional standards such as those proposed by CEN, ISO and TAUS, which focus on controlling the quality of the processes involved in the production of translations as a way of ensuring the quality of the product.

In a context where the commissioner, the purpose of a translation, the technological resources or other elements can be considered when assessing translations, quality is pictured as a dynamic construct that changes as it is affected by different factors interacting in the production and reception of translations. The notion of quality is then defined by the needs and circumstances of the agents who engage with the translation: different translation scenarios manifest different implicit and constantly evolving notions of quality depending on the specificities of the given scenario. As Miguel Jiménez-Crespo $(2017,122)$ puts it: "[The] internalized frameworks of what an ideal or adequate translation should look like diverge between different communities of practice, geographic locations, user's expectations or evaluation contexts".

Irrespective of the complexity of the concept of quality in TS and the difficulty of defining it, both academics and those in the industry have made attempts to understand and operationalize it. It could be said that the discussions have agreed only that quality is a relational concept: there cannot be an overarching idea of ultimate quality as an absolute but there are rather many possibilities for it.

Quality evaluation plays a key role in the industry because language service providers need to assure their clients that they are delivering suitable translations. It is widely accepted now that quality works on a scale that could, for instance, range from fit-for-purpose to top publishable (Vandepitte 2017; TAUS 2017; Jiménez-Crespo 2017). Regardless of the specificities, the client-provider exchange is still based on a certain agreement about quality. Thus, companies need mechanisms to show their clients they are providing services which fulfill the client's needs and expectations in terms of quality. Professional translators also need to refer to quality because that is one of the ways they can signal professionalism (Pym 2014). Just as the industry needs to talk about quality (O'Brien 2012), in academia, quality is both discussed from theoretical perspectives (House 2014; Williams 2009) and constantly assessed using empirical inquiry (Colina et al. 2017; Guerberof 2009; Specia, Raj, and Turchi 2010). Translator trainers need to subscribe to frameworks within which they can assess the quality of their students' translations and make sure that novice translators, through training, can improve the quality of their translations. 
Considering the functional approaches to quality and the imperative of discussing quality in TS, Andrew Chesterman (2004) proposes to think about translation quality in terms of two types of relations: the production conditions and the reception conditions. In terms of the production, the consideration of the conditions allows for an understanding of the translator's circumstances. Are translators provided with enough time and resources required for the translation? Is the process of translation supported by other human and non-human agents? The framework the translators have to make their decisions is defined by their relations with these aspects; their actions are constrained by the possibilities under which they operate. In terms of reception, the model gives responsibility and relevance to the recipients of the translation. Even though the recipients normally do not have the capacity to read the source language and compare the source and target texts, they should trust the translation and formally accept (or reject) it as the translation of the source material in which they are interested. Ultimately, it is their use of the translations and their positive feedback (or lack thereof) that confirms the validity of the translation.

The holistic view of translation quality put forward by Chesterman is particularly useful for the case of NPS. In these subtitling settings, users are involved on both sides of the equation - production and consumption - and implicit or explicit messages are exchanged between the agents interacting on both ends. On the consumption side, there is a large group of recipients waiting for the translation to be provided, while on the production side, a subset of this group, normally self-selected, is willing to provide a translation according to the needs and expectations of the community. The interactions and constraints on these two sides allow us to assess the functional quality of the product. Here, another concept put forward by Chesterman $(1993 ; 1997)$ proves to be particularly useful: expectancy norms. According to Chesterman, "[e]xpectancy norms are established by the expectations of readers of a translation (of a given type) concerning what a translation (of this type) should be like" (Chesterman 1997, 64).

The concept of expectancy norms can be aptly adapted to the situation of non-professional translations. NPS communities normally emerge from the discomfort of the audiences. The existence of their translations denounces a lack of compliance with the expectations held by the recipients of the translations. Fansubbing arose in response to viewer complaints about the sanitization and censorship of mainstream translations, and the lack of distribution of anime outside Japan (Cubbison 2005). The mainstream translations offered to viewers did not measure up to the ideas they had about translation quality. This initial fansubbing movement 
was characterized by a strong source-orientedness and a strong opposition to well-established professional subtitling rules, such as positioning on the screen, condensation and omission (Díaz Cintas and Muñoz Sánchez 2006; Gambier 2013). As fansubbing grew and adapted to other genres and types of content, different sets of expectations were shaped for nonprofessional subtitlers. Once viewers realized they could use the resources at their disposal to create subtitles, they started to form communities to create their own subtitles. Their reactions can be interpreted as a complaint about the translations they were offered. Some communities were not necessarily against professional subtitling guidelines; rather, they wanted to replicate what they recognized as good subtitling and produce high-quality content. Specific guidelines varied, but they often set a maximum of two lines per subtitles and about forty characters per line. They also included instructions about grammar, punctuation and spelling. They aimed at professional standards within an amateur context, similarly to what Charles Leadbeater and Miller (2004) call pro-am activities. The inconveniences denounced by some of these groups were not necessarily restricted to the censorship or alterations in the subtitles. They were reacting primarily against the lengthy international release schedules that put them in a disadvantageous position in comparison to other users. At the time, they had to wait for months or years for the audiovisual content to be released in their countries and territories. Other communities were not so worried about the subtitles as such but rather focused on increasing the circulation of content, be it as a form of activism or as a way of promoting underground productions (see Pérez-González 2010, 2012).

In trying to fulfill their expectations and those of their peers, non-professional subtitlers themselves have taken on the translation and distribution task, thus appropriating roles that used to belong to different, formal agents in the translation production and content distribution chain. They have created networks that allow them to have a semi-universal multilingual dialogue. The large-scale nature of their activities and the effort they invest in their communities are evidence that their expectations in relation to translation were not being fulfilled by traditional and official channels. They decided to produce subtitles for themselves and make them available to other users. Under these circumstances, users might become more conscious about translation and, as a result, more aware of what translation entails.

\section{Exploring quality from a functional quality perspective}

To apply Chesterman's proposition of functional quality, in what follows I will highlight some of the key findings of a series of studies exploring non-professional subtitling (Orrego- 
Carmona 2011, 2014, 2015, 2016b; Pym, Orrego-Carmona, and Torres-Simón 2016; OrregoCarmona and Richter 2018). By analyzing the production of reception conditions of nonprofessional subtitling, this review will explore the phenomenon from a holistic perspective and provide a new overview of the NPS communities under consideration. The studies reported here are based on one type of collaborative subtitling communities that I call pro-am subtitling communities (Orrego-Carmona 2016b) . These communities try to replicate most of the aspects they see in professional subtitling. The studies presented here draw on the activities of aRGENTeaM (http://www.argenteam.net/) and GrupoTS (http://grupots.net/), two non-professional subtitling communities translating subtitles into Spanish.

The rationale behind these studies can be traced back to the prescriptive focus and the limited view of quality that was present in some of the initial studies of non-professional subtitling. Additionally, the studies challenge the assumption that non-professional subtitles should not be studied from an academic perspective because they do not follow structured production processes (Bogucki 2009), or because studying them is detrimental to the translation profession (Cornu 2013). Using a holistic framework to discuss functional quality, this article provides a new overview of the combined findings, instead of the specific results presented in the individual previous publications.

\section{aRGENTeaM and GrupoTS}

The studies reviewed in this article explore two NPS communities: aRGENTeaM and GroupTS. These two communities share some characteristics, which allows common assumptions about non-professional subtitling to be tested. Both communities started as forums back in 2003 and, at the time of the studies analyzed here, had been operative for more than ten years. The continuity of their activities allows us to assume that they have managed to develop internal working mechanisms that make it possible for them to cater for and maintain a stable community of users. Both communities primarily provide subtitles in Spanish for US TV series and films, although other products in languages other than English can also be occasionally offered.

Both groups provide soft subtitles, that is to say, their translations are distributed as plain-text subtitle files and they do not embed the subtitles in the video, as some fansubbing groups do. As mentioned above, this is in line with their pro-am attitude since the subtitles are then played with the videos by the users and are often displayed with the default settings of the video player. These settings tend to replicate the format commonly used by professional 
subtitlers: subtitles are placed at the bottom of the screen and displayed in white, sans-serif font.

The main difference between the two groups is the variety of Spanish they use in their subtitles. aRGENTeaM started in Argentina, caters primarily for Latin American users and, consequently, claims to translate into neutral Spanish. GrupoTS is based in Spain and its subtitles use Iberian Spanish.

\section{The production conditions}

Exploring the production conditions of non-professional subtitling implies analyzing how NPS communities operate and how their translations come to be. Online communities can be formed around specific audiovisual genres, such as NPS communities translating anime, or the audiovisual products from a given country. Also, larger communities can offer subtitles for a wider selection of products, sometimes also in multiple languages. The motivations and structures of the communities may vary considerably, as does the number of people actively engaging in them. The main feature these communities have in common, apart from producing subtitles, is their reliance on the Internet and various technological resources. The Internet allows them to (1) overcome geographical barriers to join forces regardless of the physical location of the members and (2) to access the resources (such as forum rooms, subtitling content, raw content) they need to perform their tasks.

In the case of the communities studied here, their interest in reproducing professional subtitling with what they consider good quality standards reflects their position in relation to quality. This is a defining element in the production conditions, since it shows that their expectations still align, at least partially, with those they hold for professional subtitling. As explained in Pym, Orrego-Carmona, and Torres-Simón (2016):

Both aRGENTeaM and GrupoTS/TusSeries aim to produce subtitles with a quality similar to that of professional subtitles. They have defined and revised a set of subtitling guidelines that, although not as comprehensive as those of most subtitling agencies, indicate their concern for standardisation and compliance with professionally accepted practices $(2016,46)$.

Their guidelines detail the number of lines that subtitles should have, discuss grammar and punctuation, and provide instructions on spotting. The effort the groups have put into defining these guidelines reveals their interest in making their subtitles consistent. As is the case of 
professional standards, NPS communities use these guidelines as a way of ensuring the quality of the products. A close analysis of the guidelines put together by aRGENTeaM in their forum revealed that "the group explicitly includes 19 out of the total 26 standards" (Orrego-Carmona 2016b, 224) defined by the Code of Good Subtitling (Carroll and Ivarsson 1998). During interviews with members of aRGENTeaM (Orrego-Carmona 2011), quality emerged as one of the most relevant issues. Most of the interviewees mentioned that they had first approached the group because of the good quality of the subtitles. It was only after that initial approach as users that they became engaged in the production of subtitles. For instance, Participant 2 in Orrego-Carmona (2011) stated that he found the subtitle website while browsing on the internet but immediately thought "the subtitles were very good in comparison to other websites". Interviewees emphasized synchronization, punctuation, and grammar. aRGENTeaM's guidelines mention that the main role of the reviewer is to make sure that the translation includes everything that is said in the original and that is loyal to the original.

The level of control in the groups is not restricted to the regulation of the subtitles. The groups have also formalized the roles performed by their members, and their workflows can actually be compared to those of professional translation companies (Orrego-Carmona 2011; Pym, Orrego-Carmona, and Torres-Simón 2016). Even though all members participate in the production of subtitles, their tasks and functions vary. As expected, the groups have translators, members who are in charge of doing the translating properly speaking. Additionally, the communities have put in place a revision stage as part of the subtitle production process. Since translations are normally produced by more than one person and translators could be the newest members in the teams, revisers are responsible for putting all segments of a file together, ensuring that the guidelines are thoroughly applied, and resolving any remaining issues in the translation. There is also a layer of management to ensure the groups function well. Management is normally the responsibility of the main administrator, who oversees the group's activities and is responsible for formal issues such as website hosting. There are also middle-ranking moderators or administrators who have more narrowly defined and targeted tasks, such as coordinating the selection of products to translate and supervising the teams responsible for translating.

The tasks necessary for the completion of the subtitling activities are specialized and require competences that new members do not necessarily have. Group members are expected to comply with tight schedules and constantly interact with their peers. Members should also make sure they learn about the intricacies and requirements of the group's mechanisms since 
it is important that everyone perform their tasks consistently and within what is expected from the group. Members need to abide by the framework and guidelines that have been defined by the group. To ensure that new members can be fully integrated into the subtitling teams, the communities have developed mentoring systems (Orrego-Carmona 2011). New members are assigned specific tasks and are offered feedback by more senior members. These processes, similar to those followed by language service providers, ensure that the group members are ready to deliver translations according to the standards defined by the group.

Apart from their specific translation training, members are also required to develop the technical skills necessary for the completion of the tasks. In the case of the translators, this refers mainly to the use of subtitling software. Members are expected to master the software programs they will need to perform their tasks. To do that, they need to invest time in becoming familiar with the tools they will need to use. In the same way that the groups have developed guidelines for subtitling, they have also created tutorials and guidelines for using the necessary software. In some cases, the groups have gone even further and developed scripts that automate routine tasks and decrease the workload of group members.

The production conditions of non-professional subtitles in the communities that were studied depict a highly controlled setting in which tasks and roles are clearly defined. Likewise, the process of subtitling proper is also regulated and systematized. It is evident these groups depend highly on collaboration as a way of supporting each other towards the fulfillment of the tasks required to complete their activities. The structures and mechanisms these groups have developed reveal an understanding of what they expect from a good translation, as well as how they expect these good translations to be produced and distributed to viewers. The production process and the requirements these groups have set for the people who engage in producing the subtitles show that, as much as language service providers, these groups also operate on the assumption that controlling the quality of the production process serves to produce a good quality translation.

\section{The reception conditions}

Exploring the reception conditions of non-professional subtitles is more complicated than analyzing the production side of the equation. While only a small group of people are engaged in the production of subtitles, the subtitles may be used by hundreds or thousands of people. To approach the reception side and as an attempt to assess how people feel about nonprofessional subtitling, whether they use them and what the impact of these subtitles is, I 
carried out an experiment to study the reception of non-professional subtitles at the Universitat Rovira i Virgili in 2013 (Orrego-Carmona 2014, 2015, 2016a), and collected and analyzed Internet data (Orrego-Carmona 2014; Orrego-Carmona and Richter 2018). To operationalize reception, I relied on Gambier's proposal to study reception at three levels: "reactions on the cognitive level, responses in behavioural terms and repercussions of a cultural order" (Gambier 2008, emphasis in the original).

In the experiment on the reception of non-professional subtitles, participants were university students (between 18 and 30 years of age) who were native speakers of Catalan or Spanish and regular users of audiovisual content. Prior to the experiment, the participants took a purposefully designed language test to assess their listening comprehension. Only participants with a high and a low level of proficiency in English were included in the study. During the experiment, the participants answered two questionnaires, completed an eyetracking session and participated in an interview.

In terms of audiovisual consumption habits, the questionnaires revealed that even though Spain is primarily a dubbing country, $63 \%$ of the participants used subtitles occasionally or very frequently, with some of them even resorting to closed caption in cases when there were no regular subtitles available for the products they wanted to watch (OrregoCarmona 2015). This is already an indicator that audiences are not only open to less familiar translation practices but also to changing the conditions of international media flows (OrregoCarmona 2018). However, this cannot be taken as a complete change in the tradition of the country. Twitter data on the broadcasting of a subtitled version of Game of Thrones on Canal+ Spain in 2014 revealed that for some viewers, subtitling is not really a valid option when it comes to enjoying the audiovisual content. They claim they do not understand the English audio, find the original voices odd and are not used to subtitles, so they say they cannot read them (Orrego-Carmona 2014). Additionally, those who use subtitles do not necessarily consider them as their first option. The participants in the interview still prefer dubbed versions because they feel dubbing makes it easier to follow and understand the content; however, since subtitled versions, particularly NPS, are often available before the dubbed versions the participants are willing to put up with the subtitles to keep up with the new episodes coming out.

The participants not only reported using the subtitles but also expressed a highly conscious view of them. Half of the participants had a high level of proficiency in English according to the test and felt comfortable judging the translations. Some of the participants 
acknowledged that they constantly compare the original dialogues to the subtitles to assess how good the translations are (Orrego-Carmona 2015). When they feel the subtitles are not good or identify something they are not convinced of, they prefer to look for another subtitle file. The participants mentioned, for instance, that good subtitles would be synchronized, match the dialogues, not have too much text and not be too fast. This attitude is not restricted to non-professional subtitles only: the participants commented that they also assessed the material even when watching professionally subtitled videos.

Apart from talking to the participants about their habits and opinions regarding nonprofessional translation, my research has tested and compared the reception of professional and non-professional subtitles (Orrego-Carmona 2015, 2016a). In order to understand how non-professional subtitling might impact the comprehension of the content, two aspects of the participants' understanding were tested: general comprehension and recall of the narrative, verbal and iconic information in the audiovisual product (Künzli and Ehrensberger-Dow 2011). The results of the experiments do not indicate that professional subtitles correlate with better comprehension among participants. Reception capacity was similar for professional and non-professional subtitles. Additionally, the participants did not feel that they understood less nor that they had to put more effort into reading the subtitles when exposed to the nonprofessional versions produced by aRGENTeaM or GrupoTS. According to these results, viewers do not necessarily differentiate between professional subtitles and pro-am NPS. They have a similar experience using either of them. Further, their understanding of the content is not necessarily compromised. The study did find some differences in terms of eye tracking measurements related to subtitle reading (Orrego-Carmona 2015, 2016a); but, these do not seem to affect comprehension or engagement at a conscious level.

When questioned about the use of non-professional subtitles, the participants in the experiment described a rather complex and informed way of selecting and using subtitles. They acknowledged that there are different types of subtitles available on the Internet. When they feel the subtitles are not good enough for their purposes, they know they can look for alternative translations created by other groups. The viewers identified factors such as poor synchronization or spelling mistakes as indicators of poor quality that make them mistrust the translations. In the case of Spanish subtitles, users were also used to the differences between Latin American subtitles and Spanish subtitles. They recognized that subtitles are produced in these two broad varieties and used this difference as a factor to decide whether they want to rely on the subtitles. 
The discussion about quality also emerged during the interviews. For some of them, the main issue in terms of quality was not whether the subtitles were "perfect". Rather, quality seemed to be a matter of access and time: they wanted to watch the content as soon as it was released but also wanted to be able to choose when and how to watch it (Orrego-Carmona 2015). When assessing the circumstances under which they needed and used subtitles, the participants seemed to prioritize speed and access over aspects that academics and professionals have so far considered as indicators of quality, such as good synchronization or the number of characters per line. Some participants argued that since they already had some knowledge of English, they could decide whether to rely on the subtitles or not. They claimed they used the subtitles as a supporting resource and did not fully depend on them as the primary source of information. This gave the participants a sense that they could make an informed decision about whether to use and trust the subtitles, which made them empowered agents.

The relevance of speed and access is supported by the findings of Orrego-Carmona and Richter (2018). The study tracked the downloads of subtitles for the third season of House of Cards over a two-week period after the release of the third season, and found that $66.1 \%$ of the total downloads $(480,298)$ occurred during the first four days ${ }^{1}$. Users are eager to access the content and, once it is made available, rush to watch it as soon as possible. This reflects the development and popularization of binge-watching. The resources provided by NPS communities make it possible for users to maintain this type of behavior.

The interviewees also mentioned that, even though they might not prefer subtitles as a way of watching audiovisual products for enjoyment purposes, they were willing to use them to support language learning. Some of them commented that they use subtitles in the original language (Orrego-Carmona 2015). Subtitling allows them to access the original language of the audiovisual products and they consider it a tool to improve their foreign language skills. Traditionally, it has been argued that subtitles improve language proficiency and support language learning (Bisson et al. 2014; d'Ydewalle 2002). The findings of the study on the distribution of subtitles by Orrego-Carmona and Richter (2018) seem to support this idea. By far the most downloaded subtitles during the period under study were the intralingual subtitles in English, which accounted for $80.37 \%$ of all downloads. This dominance of the intralingual subtitles can be understood as an indication of a growing interest in subtitling as a language learning tool or as the viewers' intention to access the content in a form that is closer to the original. 
Exploring the reception conditions of NPS reveals the figure of empowered and wellinformed users who resort to subtitling for various purposes: users find themselves in a context in which they feel their needs are not fully covered by professional subtitling, and decide to use non-professional subtitles because they offer a wider range of options. Their decisions are not necessarily guided by linguistic precision or technical aspects. On the contrary, in these contexts, other aspects such as time and accessibility are the deciding factors.

\section{Discussion}

Exploring the production and reception conditions of NPS within the functional quality framework proposed by Chesterman (2004) allows us to distance ourselves from a languagebased, text-oriented understanding of quality. As a result, it is possible to approach NPS from a non-prescriptive angle and assess it without the need to measure it against professional translation. This change of focus opens up the possibility to consider NPS as a set of activities that respond to the expectations of a group of active consumers who are no longer satisfied with the official translations.

NPS settings challenge a basic assumption of most translation theories because it follows a "consumer-oriented model of internality" (Cronin 2012, 100). In these settings, consumers actively become producers and there is no external figure of a translator mediating between the production end and the reception end of the exchange. Volunteer translators in NPS communities are, at the same time, users and producers of content, even though nonprofessional subtitles are produced only by a minority in NPS communities (Pym 2011; Orrego-Carmona and Richter 2018). As Cronin explains, “[i]t is no longer a question of the translator, for example, projecting a target-oriented model of translation on to an audience, but of the audience producing its own self-representation as a target audience" $(2012,100)$. Non-professional subtitlers are first and foremost part of the community of users. This allows the communities to cater specifically to a sector of the audience they feel identified with. In that sense, non-professional subtitlers are in a better position than professional subtitlers who are constrained by the working conditions of the market (Abdallah 2010) and need to consider a larger and more diverse audience.

The analysis of the production and reception conditions has revealed that some NPS communities can follow well-structured and highly controlled procedures put in place to produce subtitles that respond to the needs of the audience. There is a strong connection 
between the production side and the reception side because, due to the fluidity of the communities, members have the possibility of moving from one to the other. The interviews with the volunteer translators from aRGENTeaM revealed that most of them started as users and later became translators or revisers. This is indicative of the development of trust and loyalty in the communities: users who feel satisfied with the subtitles produced by the community may feel motivated become active members of the community. The emergence and continuity of the production teams depend on maintaining a large and satisfied audience. If a community does not manage to inspire trust in its subtitles, it might fail to attract new members and compromise its existence.

The subtitle users who act as lurkers (Nielsen 2006) and not as producers might feel freer to choose from a pool of subtitles. On the reception side of NPS, one of the defining aspects is the existence of alternatives. Popular TV series and films are often translated by different NPS (and in many cases, competing) groups. The users of the translations find themselves in a privileged position, as pointed out by the participants in the experiment since they do not only have the option to judge the translations but also have the possibility to compare them against other translations available. Should they not be satisfied with a certain version, they can look for an alternative that might suit them better. Access is one of the most relevant aspects in NPS: users enjoy the possibility of accessing as much content as they want and in the forms that they want. The availability of multiple options has also made users more conscious about translation and might make translation more visible to the general audience.

Subtitling, in general, has always been in the spotlight because, being an overt form of translation, it allows users to simultaneously access both the original and the translation (Díaz Cintas 2001). In a global context in which many people have at least a basic knowledge of English (Pym 2013), this might become a problem for products that are originally in English. The results of the reception studies show that viewers often compare the subtitles against the original dialogues; thus, there is a risk of viewers with limited knowledge of English judging translation decisions. For these viewers, a good-quality subtitle might be the one that follows the original and maintains a certain degree of "foreignness". NPS, at least in Europe and the Americas, tends to follow a more source-oriented approach in which everything that is said in the original needs to be translated ${ }^{2}$ (Feitosa 2009; Gambier 2014; Massidda 2015). NPS communities can do this because they serve a relatively small and self-selected audience that expects this type of approach. However, this puts professional translators at a disadvantage. Professional translators need to ensure that their translations are suitable for a larger audience 
and might adopt more target-oriented decisions after carefully assessing the options at hand. A community of users who considers the translation process as a one-to-one replacement activity might then judge adequate translation decisions as translation errors. From the users' point of view, professional translation might fail to fulfill their expectations of a more literal translation. It seems users are more and more interested in accessing a product that is ever closer to the original. The high number of downloads of subtitles in English shows that viewers are willing to use intralingual subtitles. On the one hand, they could consider intralingual subtitling a real possibility to enjoy the content and, perhaps, improve their language skills. On the other, it could be the case that subtitles in the original language (in the case of this study, English) are ready before the translations.

The re-ordering of priorities by the agents involved in NPS communities explains why NPS should not be studied within a professional translation framework. The analysis of the production and reception conditions of NPS served to discover how much viewers value fast circulation and access when it comes to subtitles. For the viewers of this type of audiovisual products, subtitles are a means to an end: enjoying the content. The new audiences of audiovisual content are used to using the Internet as a window to access everything they want, and subtitles play but a part in the whole system. Viewers know how to select the type of subtitles that responds to what they want. For them, the most relevant aspects when using NPS are availability and time efficiency. They want to make sure the subtitles will be there for them to access the content, but they also want those subtitles to be ready as soon as the content is made available. Among the elements that define quality for them, speed and access are the most highly ranking factors.

\section{Conclusion}

Considering quality from a holistic perspective, the analysis of the production and reception conditions of NPS suggests that these subtitles fulfill the expectations of viewers and can be considered adequate translations within their pre-established framework. These results were only possible because the study of NPS settings proposed here was undertaken considering a wider notion of quality. Instead of analyzing quality from a prescriptive product-oriented angle, the exploration of the notion of quality implicit in the context allowed for a better understanding of the phenomenon as a whole.

Chesterman's proposal to study quality as a functional concept that encompasses the production and reception conditions in relation with the translator provides a robust and 
flexible framework to analyze quality as an evolving concept. By large, the main benefit of the framework is that it allows for the existence of different levels of quality that arise from the constraints imposed on the production process and the conditions under which translations are consumed. The framework gives relevance to the way translators are affected by these conditions. Factoring in the conditions under which translators operate in the assessment of quality in the contexts of NPS, where translators are members of the user community, provides researchers with better tools study quality and its implications. Analyzing quality on a case-by-case basis, rather than as an absolute, also allows for the co-existence of different types of quality for different groups of users. However, studying quality within this framework is not necessarily easy. In order to be able to assess quality, researchers need to thoroughly understand the production and reception conditions of the products and their relations with the translators. This implies time-consuming and detailed analysis of all the agents involved in the process, including a definition of the elusive concept of audience, the group of users of translations. While TS has explored the production conditions of translation, the study of audiences and reception remains an underdeveloped area that requires further attention if this framework is to be applied. Although the framework has the capacity to accommodate different understandings, the above-mentioned factors need to be defined and studied to be able to assess how quality should be conceived in each case.

Non-professional translations are created for people with well-defined needs, and these users have their expectations of availability and quality satisfied by NPS. These translations often co-exist with their professional counterparts. NPS occupies a place in the international media flows and seems to respond to the needs of a segment of the audience. Scholarly attention is needed to understand the societal impact of non-professional practices. Defining translation as encompassing only professional manifestations in professional settings is restrictive and ill-advised. Translation is first and foremost an essential part of human communication. While it is understandable that professionals may not want to become engaged with NPS, this is not an option for TS.

The holistic approach that was proposed here combining Chesterman's considerations of functional quality and his expectancy norms provides a basis to study NPS subtitling in context. This is a first contribution towards more solid and richer studies of NPS. Future projects can expand on these ideas and analyze other NPS settings to explore the social impact and the changes initiated by the activities of NPS communities. The study of volunteer translation in the digital age is still in its infancy but the rapidly paced technological 
developments that allow for this type of translation makes it hard for scholars to keep up with all the changes. Up to now, the different case studies that have been carried out have helped to establish NPS as a legitimate area of research, but the phenomenon is yet to be fully addressed from a more encompassing framework. Exploring new translation spaces will enlarge our understanding of translation and the role of it plays in a global context. Translation activities in the digital age deserve attention, not only because they put translation in the everyday lives of Internet users, viewers and the general audience, but also because they expand the societal impact of translation. These activities have the potential to foster development in translation both as a social activity and as a profession.

\section{Disclosure statement}

No potential conflict of interest was reported by the author.

\section{Note on contributor}

David Orrego-Carmona is a lecturer in translation studies at Aston University (UK) and an associate research fellow at the University of the Free State (SA). After completing a BA in translation at the Universidad de Antioquia (Colombia) and working as an in-house translator, he obtained an MA (2011) and a PhD (2015) in translation and intercultural studies from the Universitat Rovira i Virgili in Tarragona (Spain). His research analyses how translation technologies empower users and how the democratization of technology allows them to become translators. He is also interested in the cognitive exploration of translation production and reception, mainly using eye tracking technologies.

\section{References}

Abdallah, Kristiina. 2010. “Translators' Agency in Production Networks.” In Translators' Agency, edited by Tuija Kinnunen and Kaisa Koskinen, 11-46. Tampere Studies in Language Translation and Culture. Series B 4. Tampere: Tampere University Press. http:/tampub.uta.fi/tup/978-951-44-8082-9.pdf.

Bisson, Marie-Josée, Walter J. B. van Heuven, Kathy Conklin, and Richard Tunney. 2014. "The Role of Repeated Exposure to Multimodal Input in Incidental Acquisition of Foreign Language Vocabulary.” Language Learning 64 (4): 855-77.

Bogucki, Łukasz. 2009. "Amateur Subtitling on the Internet." In Audiovisual Translation: Language Transfer on Screen, edited by Jorge Díaz Cintas and Gunilla Anderman, 49-57. Basingstoke: Palgrave Macmillan. 
Carroll, Mary, and Jan Ivarsson. 1998. "Code of Good Subtitling Practice." https://www.esist.org/code-of-good-subtitling-practice/.

Catford. 1965. A Linguistic Theory of Translation: An Essay in Applied Linguistics. Language and language learning. Oxford: Oxford University Press.

Chesterman. 1997. Memes of Translation: The Spread of Ideas in Translation Theory. Benjamins translation library 22. Amsterdam, Philadelphia: John Benjamins Publishing Company.

Chesterman, Andrew. 1993. "From 'Is' to 'Ought': Laws, Norms and Strategies in Translation Studies." Target, International Journal of Translation Studies 5 (1): 1-20. doi:10.1075/target.5.1.02che.

Chesterman, Andrew. 2004. "Functional Quality." Unpublished Lecture, Tarragona, 2004. Accessed February 28, 2015. https://www.youtube.com/watch?v=IJW1Y6rAB1I.

Colina, Sonia, Nicole Marrone, Maia Ingram, and Daisey Sánchez. 2017. "Translation Quality Assessment in Health Research: a Functionalist Alternative to Back-Translation." Evaluation \& the health professions 40 (3): 267-93. doi:10.1177/0163278716648191.

Cornu, Jean-François. 2013. "De Barcelone aux bords du Rhin : Le Doublage et le soustitrage au fil des congrès." L'écran traduit 2 ((automne 2013)): 107-22. http://ataa.fr/revue/archives/2162.

Cronin. 2012. Translation in the Digital Age. London, New York: Routledge.

Cubbison, Laurie. 2005. "Anime Fans, DVDs, and the Authentic Text." The velvet light trap 56 (1): 45-57. Accessed January 29, 2010.

d'Ydewalle, Géry. 2002. "Foreign-Language Acquisition by Watching Subtitled Television Programs." Accessed January 2015. http://www.kansaiu.ac.jp/f1/publication/pdf_education/04/4geryd'ydewalle.pdf.

Díaz Cintas. 2001. La traducción audiovisual: El subtitulado. Biblioteca de traducción 6. Salamanca: Ediciones Almar.

Díaz Cintas, Jorge, and Pablo Muñoz Sánchez. 2006. "Fansubs: Audiovisual Translation in an Amateur Environment." JoSTrans, The Journal of Specialised Translation 6: 37-52. http://www.jostrans.org/issue06/art_diaz_munoz.php.

Feitosa, Marcos Pereira. 2009. "Legendagem Comercial e Legendagem Pirata: Um Estudo Comparado." Postgraduate thesis, Faculdade de Letras da UFMG.

Fernández Costales, Alberto. 2012. "Collaborative Translation Revisited: Exploring the Rationale and the Motivation for Volunteer Translation." Forum 10 (1): 115-42.

Ferrer Simó, María Rosario. 2005. "Fansubs y scanlations: La influencia del aficionado en los criterios profesionales." Puentes 5: 27-44. http://www.ugr.es/ greti/puentes/puentes6/04\%20Maria\%20Rosario\%20Ferrer.pdf.

Gambier, Yves. 2008. "Recent Developments and Challenges in Audiovisual Translation Research." In Between Text and Image: Updating Research in Screen Translation, edited by Delia Chiaro, Christine Heiss, and Chiara Bucaria, 11-36. Benjamins translation library 78. Amsterdam, Philadelphia: John Benjamins Publishing Company. 
Gambier, Yves. 2013. "The Position of Audiovisual Translation Studies." In The Routledge Handbook of Translation Studies, edited by Carmen Millán and Francesca Bartrina, 45-59. Routledge handbooks in applied linguistics. London, New York: Routledge.

Gambier, Yves. 2014. "Changing Landscape in Translation." International Journal of Society, Culture \& Language 2 (2): 1-12.

Guerberof, Anna. 2009. "Productivity and Quality in MT Post-Editing." In Proceedings of MT Summit XII: The twelfth Machine Translation Summit International Association for Machine Translation hosted by the Association for Machine Translation in the Americas. http://www.mt-archive.info/MTS-2009-Guerberof.pdf.

Hanes, William Franklin. 2011. "A Cultura de Fansubs Sob o Olhar dos Estudos da Tradução.” Cultura \& Tradução 1 (1): n.p. http://periodicos.ufpb.br/ojs/index.php/ct/article/view/13022.

House, Juliane. 2014. “Translation Quality Assessment.” In Translation: A Multidisciplinary Approach, edited by Juliane House, 241-64. Basingstoke: Palgrave Macmillan.

Jiménez-Crespo. 2017. Crowdsourcing and Online Collaborative Translations. Benjamins translation library 131. Amsterdam, Philadelphia: John Benjamins Publishing Company.

Jiménez-Crespo, Miguel A. 2015. "Collaborative and Volunteer Translation and Interpreting." In Researching translation and interpreting, edited by Claudia Angelelli and Brian J. Baer, 58-70. London, New York: Routledge.

Künzli, Alexander, and Maureen Ehrensberger-Dow. 2011. "Innovative Subtitling: A Reception Study." In Methods and Strategies of Process Research: Integrative Approaches in Translation Studies, edited by Cecilia Alvstad, Adelina Hild, and Elisabet Tiselius, 187200. Benjamins translation library 94. Amsterdam, Philadelphia: John Benjamins Publishing Company.

La Forgia, Francesca, and Raffaella Tonin. 2009. "In un Tranquillo Week-End di Paura, un Esorcista Volò sul Nido del...: Un Case Study sui Rimandi Intertestuali nel Sottotitolaggio e Doppiaggio Italiano e Spagnolo della Serie Supernatural.” inTRAlinea 11: n.p. http://www.intralinea.org/archive/article/In_un_tranquillo_weekend_di_paura_un_Esorcista.

Leadbeater and Miller. 2004. The Pro-Am Revolution: How Enthusiasts Are Changing our Society and Economy. London: Demos.

Massidda. 2015. Audiovisual Translation in the Digital Age: The Italian Fansubbing Phenomenon. Basingstoke: Palgrave Macmillan.

Nida. 1964. Toward a Science of Translating: With Special Reference to Principles and Procedures Involved in Bible Translating. Leiden, Boston: Brill.

Nielsen, Jakob. 2006. "The 90-9-1 Rule for Participation Inequality in Social Media and Online Communities.” Accessed November 10, 2017. http://www.nngroup.com/articles/participation-inequality/.

Nord. 1997. Translating as a Purposeful Activity: Functionalist Approaches Explained. Translation theories explained 1. Manchester, UK: Saint Jerome Publishing.

Nornes, Abé Mark. 1999. "For an Abusive Subtitling.” Film Quarterly 52 (3): 17-34. 
O’Brien, Sharon. 2012. "Towards a Dynamic Quality Evaluation Model for Translation." JoSTrans, The Journal of Specialised Translation 17: 55-77.

http://www.jostrans.org/issue17/art_obrien.pdf.

O’Hagan, Minako. 2009. “Evolution of User-Generated Translation: Fansubs, Translation Hacking and Crowdsourcing." The Journal of Internationalisation and Localisation (1): 94-121.

O’Hagan, Minako. 2011. "Community Translation: Translation as a Social Activity and its Possible Consequences in the Advent of Web 2.0 and Beyond." Linguistica Antverpiensia 10: 11-23. http://www.lans-tts.be/docs/lans10-2011-intro.pdf.

Orrego-Carmona, David. 2011. "The Empirical Study of Non-Professional Subtitling: A Descriptive Approach.” Master's minor dissertation, Intercultural Studies Group, Universitat Rovira i Virgili.

Orrego-Carmona, David. 2014. "Subtitling, Video Consumption and Viewers: The Impact of the Young Audience.” Translation Spaces 3:51-70. doi:10.1075/ts.3.03orr.

Orrego-Carmona, David. 2015. "The Reception of (Non)Professional Subtitling." PhD thesis, Universitat Rovira i Virgili.

Orrego-Carmona, David. 2016a. "A Reception Study on Non-Professional Subtitling: Do Audiences Notice Any Difference?” Across Languages and Cultures 17 (2): 163-81. doi:10.1556/084.2016.17.2.2.

Orrego-Carmona, David. 2016b. "Internal Structures and Workflows in Collaborative Subtitling." In Non-professional Interpreting and Translation in the Media, edited by Rachele Antonini and Chiara Bucaria, 211-30. Bern: Peter Lang.

Orrego-Carmona, David. 2018. "New Audiences, International Distribution, and Translation." In Reception Studies and Audiovisual Translation, edited by Yves Gambier and Elena Di Giovanni, 321-42. Amsterdam, Philadelphia: John Benjamins Publishing Company.

Orrego-Carmona, David, and Simon Richter. 2018. "Tracking the distribution of nonprofessional subtitles to study new audiences." $O B S^{*} 12$ (4): 64-86. doi:10.15847/obsOBS12420181300.

Pérez-González, Luis. 2010. "'Ad-Hocracies' of Translation Activism in the Blogosphere: A Genealogical Case Study." In Text and Context: Essays on Translation \& Interpreting in Honour of Ian Mason, edited by Mona Baker, Maeve Olohan, and María Calzada Pérez, 259-87. Manchester, UK, Kinderhook, NY: St. Jerome Pub.

Pérez-González, Luis. 2012. "Co-Creational Subtitling in the Digital Media: Transformative and Authorial Practices." International Journal of Cultural Studies 16 (1): 3-21. doi:10.1177/1367877912459145.

Pym, Anthony. 2011. "Translation research terms: a tentative glossary for moments of perplexity and dispute.” In Translation Research Projects 3, edited by Anthony Pym, 75110. Tarragona: Intercultural Studies Group.

Pym, Anthony. 2013. "Inculturation as Elephant: On Translation and the Spread of Literary Modernity." In Perspectives on Literature and Translation: Creation, Circulation, 
Reception, edited by Brian Nelson and Brigid Maher, 87-104. Routledge advances in translation studies 5. London, New York: Routledge.

Pym, Anthony. 2014. "Translator Associations — From Gatekeepers to Communities." Target, International Journal of Translation Studies 26 (3): 466-91. doi:10.1075/target.26.3.06pym.

Pym, Anthony, David Orrego-Carmona, and Esther Torres-Simón. 2016. "Status and Technology in the Professionalization of Translators: Market Disorder and the Return of Hierarchy." JoSTrans, The Journal of Specialised Translation (25): 33-53. http://www.jostrans.org/issue25/art_pym.php.

Reiss and Vermeer. 2015. Towards a General Theory of Translational Action: Skopos Theory Explained. London, New York: Routledge.

Sajna, Mateusz. 2013. "Amateur Subtitling: Selected Problems and Solutions.” T21N Translation in Transition 3: 1-18. http://www.t21n.com/homepage/articles/T21N-2013-03Sajna.pdf. Accessed December 30, 2014.

Specia, Lucia, Dhwaj Raj, and Marco Turchi. 2010. "Machine Translation Evaluation Versus Quality Estimation.” Machine Translation 24 (1): 39-50. doi:10.1007/s10590-010-9077-2.

TAUS. 2017. "TAUS DQF Enterprise User Group. Topic \#2: DQF Quality Levels Resolution." https://www.taus.net/file-downloads/downloadfile?path=DQF\%2FEUG_Resolution-2_QualityLevels.pdf.

Vandepitte, Sonia. 2017. “Translation Product Quality: a Conceptual Analysis.” In Quality Aspects in Institutional Translation, edited by Tomas Svoboda, Łucja Biel, and Krzysztof Łoboda, 15-29. Translation and Multilingual Natural Language Processing 8. Berlin: Language Science Press.

Wilcock, Simone. 2013. "A Comparative Analysis of Fansubbing and Professional DVD Subtitling." Master's thesis, University of Johannesburg. http://hdl.handle.net/10210/8638.

Williams, Malcolm. 2009. “Translation Quality Assessment.” Mutatis Mutandis 2 (1): 3-23. http://aprendeenlinea.udea.edu.co/revistas/index.php/mutatismutandis/article/view/1825/16 09.

\footnotetext{
${ }^{1}$ Downloads were tracked from the website addic7ed.com, a multilingual NPS platform. Figures include downloads in nine languages: Bulgarian, Dutch, English, French, Italian, Portuguese, Persian, Russian and Spanish.

${ }^{2}$ My research deliberately focuses on the reception and production conditions, not on the subtitled products. Other studies have identified source-orientedness (e.g Feitosa 2009; Wilcock 2013; Massidda 2015).
} 